\title{
Przygotowanie populacji mapującej uzyskanej ze skrzyżowania odmian 'Elsanta' i 'Senga Sengana' dla analizy regionów QTL sprzężonych z wybranymi cechami użytkowymi gatunku Fragaria.
}

\author{
Preparation of the mapping population derived from the cross of 'Elsanta' \\ and 'Senga Sengana' sutble for analysis of QTL regions linked to selected Fragaria \\ traits.
}

\section{Sylwia Keller-Przybyłkowicz ${ }^{\oplus 凶}$, Agnieszka Masny $^{\oplus 1}$, Bogusława Idczak ${ }^{\circledast 1}$, Krystyna Strączyńska ${ }^{\oplus 1}$, Abdelrahmen Mostafa Abdelwahab Mohamed ${ }^{\circledast 2}$}

\author{
1 Zakład Hodowli Roślin Ogrodniczych, Instytut Ogrodnictwa, ul. Konstytucji 3 Maja 1/3, 96-100 Skierniewice, \\ 2 Minia University, Faculty of Agriculture, 61517 Elminia, Egypt, \\ $\triangle$ e-mail: sylwia.keller@inhort.pl
}

\begin{abstract}
Celem przeprowadzonych badań było przygotowanie populacji mapującej uzyskanej w wyniku skrzyżowania odmian 'Elsanta' i 'Senga Sengana', przydatnej do badań genotypowo-fenotypowych, poprzedzonych sporządzeniem 'szkieletu' mapy genetycznej.

Pierwszym etapem badań była ocena molekularna roślin form rodzicielskich pod kątem stopnia polimorfizmu genetycznego. Na postawie analizy wytypowanych 450 markerów SSR w genomie odmiany 'Elsanta' zidentyfikowano łącznie 418 alleli polimorficznych, natomiast w genomie odminay 'Senga Sengana' - 337 alleli. Przeprowadzone badania potwierdzają wysoki stopień heterozygotyczności genomów obu wytypowanych do badań odmian.

Kolejnym etapem prac była analiza molekularna siewek uzyskanych w wyniku krzyżowania obu heterozygotycznych form rodzicielskich oraz ocena satusu genetycznego genotypów potomnych. Badania te potwierdziły, że w obrębie roślin populacji mapującej 'Elsanta' i 'Senga Sengana' występują genotypy pochodzące tylko z kontrolowanego zapylenia. Ponadto, analiza segregacji, w populacji mapującej, alleli heterozygotycznych, zidentyfkowanych w genomach form rodzicielskich, umożliwiła sporządzenie szkieltu zintegrowanej mapy obu badanych genomów truskawki. Wstępna mapa genetyczna, do sporządzenia której zastosowano wybranych 44 polimorficznych markerów SSR, zawiera łącznie 27 grup sprzężeń, na których zidentyfikowano loci 53 alleli polimorficznych, pokrywających $1033 \mathrm{cM}$ genomu truskawki.

W wyniku przeprowadzonych testów potwierdzono, że uzyskana populacja stanowi wartościowy materiał do badań związanych z opracowaniem mapy genetycznej truskawki. Ponadto, sporządzony 'szkielet' mapy 'Elsanta' $\times$ 'Senga Sengana’ poszerza bazę do dalszej lokalizacji genów i identyfikacji regionów QTL sprzężonych z ważnymi cechami użytkowymi truskawki.
\end{abstract}

Słowa kluczowe: allele heterozygotyczne, genom Fragaria, mapa genetyczna, SSR

\begin{abstract}
The aim of the study was to generate a mapping population derived from an 'Elsanta' and 'Senga Sengana' cross, so as to be useful for genotypic-phenotypic studies, and subsequently, to construct a 'skeleton' of the strawberry genetic map.

The first stage of the research was based on molecular assessment of parental plants for genetic polymorphism. After analysis of 450 selected SSR markers, 418 polymorphic alleles were identified in the genome of the 'Elsanta', and 337 alleles in the genome of the 'Senga Sengana'. The study confirms the high degree of genetic heterozygosity of both of the strawberry varieties.

In the next stage of the work, molecular analysis of seedlings resulted from the cross of the heterozygous parental forms, as well as the confirmation of genetic status of hybrid genotypes were conducted. These studies confirm that the origin of the prepared mapping population was the result of the controlled pollination. Moreover, segregation of heterozygous alleles in the mapping population enabled the preparation of the 'skeleton' of an integrated map of 'Elsanta' x 'Senga Sengana'. Herein, the initial genetic map was found to contain 27 linkage groups representing the loci of 53 polymorphic allele, covering $1033 \mathrm{cM}$ of the strawberry genome.

Generally, as a result of the tests, we confirmed that the obtained population represents valuable material for research related to the development of a strawberry genetic map. Additionally, the 'skeleton' of 'Elsanta' x 'Senga Sengana' genetic map enlarged the database for further gene localization and for identifying QTL regions linked to important strawberry traits.
\end{abstract}

Key words: Fragaria genome, genetic map, heterozygous alleles, SSR 


\section{Wstęp}

Truskawka (Fragaria $\times$ ananassa Duchesne ex Rozier) jest ważnym gatunkiem uprawianym niemal we wszystkich szerokościach geograficznych. Na świecie produkuje się rocznie około $9 \mathrm{mln}$ ton owoców truskawek, w tym połowę w państwach europejskich (FAOStat, 2019).

Hodowla twórcza gatunku $F$. $\times$ ananassa, ukierunkowana jest na wytwarzanie odmian, o najkorzystniejszym zestawie cech fenotypowych, przystosowanych do zróżnicowanych warunków uprawy (takich jak: zasolenie), różnych warunków agroklimatycznych (tj. mróz, susza), zróżnicowanej presji czynników biotycznych (np: choroby grzybowe tj. wertycylioza, antraknoza) i abiotycznych, jak również do zróżnicowanych preferencji konsumentów (jędrność i trwałość owoców, zawartość kwasu askorbinowego czy cukrów) (Darrow, 1966; Hancock, 2008).

Badania genetyczne, wspierające światową hodowlę tego gatunku, pozwoliły na zidentyfikowanie molekularnych markerów m.in. cech związanych z jakością owoców, zakwitaniem czy odpornością na patogeny. Dla wielu z nich, zidentyfikowano także loci/miejsce na fragmentarycznych mapach genetycznych różnych genomów tego gatunku (Denoyes-Rothan i in. 2004; 2005, Sargent $i$ in. 2011, Sargen i in. 2012).

$\mathrm{Na}$ podstawie doświadczeń genetycznohodowlanych stwierdzono zarówno monogeniczny (odporność na fytoftorozę i alternariozę), jak i poligeniczny charakter dziedziczenia cech użytkowych truskawki (Lerceteau-Kohler i in., 2002). W wyni$\mathrm{ku}$ addytywnego (poligenowego) współdziłania genów ma miejsce kumulacja ich alleli w genomie, a każdy genotyp wykazuje inną chrakterystykę fenotypową, zależnie od własnego potencjału genetycznego (Semagn i in., 2006; Hancock i in. 2008). Ma to szczególne znaczenie podczas prowadzenia badań, których celem jest sporządzanie map różnych genomów. Wówczas warunkiem przystąpienia do takich prac jest uzyskanie odpowiedniej puli roślin potomnych tzw. populacji mapującej, (przyjmuje się min. 100 - 150 genotypów mieszańcowych), w obrębie której wszystkie genotypy pochodzą z zaplanowanego krzyżowania, a formy rodzicielskie reprezentują wysoki stopień heterozygotyczność (Liebhard i Gessler 2000). Podejście takie daje pewność prawidłowej analizy segregacji zidentyfikowanych alleli markerów molekularnych, przydatnych do wysycaania map genetycznych. Właściwy dobór i przygotowanie materiału roślinnego są zatem kluczowymi etapami w badaniach nad identyfikacją regionów genomu warunkujących ważne cechy użytkowe gatunku Fragaria.

Celem prowadzonych badań było przygotowanie populacji mapującej, przydatnej do utworzenia 'szkieletu' mapy genomu i identyfikacji regionów genomowych (QTL) sprzężonych z ważnymi cechami użytkowymi truskawki takimi jak: odporność na choroby wywołane grzybami ( $V$. dahliae, Colletotrichum acutatum, Phytophthora cactorum); jakość owoców (zawartość substancji prozdrowotnych); odporność na czynniki abiotyczne tj; tolerancja na niskie temperatury czy deficyt wody) .

\section{Materiały i Metody}

Materiał do badań stanowiły rośliny mieszańcowe, uzyskane w wyniku krzyżowania roślin rodzicielskich odmian 'Elsanta' i 'Senga Sengana' (CP - cross polination). Wybrane formy rodzicielskie skrajnie różnią się pod względem wielu cech, w tym podatności na czynniki biotyczne i abiotyczne oraz jakością owoców (Van Ooijen 2002, Masny $i$ in. 2002).

\section{Przygotowanie materialu roślinnego}

Nasiona, uzyskane w programie krzyżowań (2014), po wysuszeniu i stratyfikacji wysiewano do doniczek wypełnionych mieszaniną substratu torfowego i piasku w stosunku 3:1. Pozyskane tym sposobem młode siewki potomne (200 roślin), stanowiące populację mapującą, $w$ fazie minimum dwóch liści przesadzono do tac wielodoniczkowych (54 komórki o wymiarach $55 \times 55 \times 62 \mathrm{~mm}$ i objętości $90 \mathrm{~cm}^{3}$ ). Rośliny utrzymywano w szklarni. Następnie uzyskane młode siewki wysadzono w kwaterze polowej. Systematycznie prowadzono prace uprawowo-pielęgnacyjne, jak nawadnianie i nawożenie uzyskanych roślin, spulchnianie podłoża oraz zwalczanie chorób i szkodników (Program Ochrony Roślin, opryski na mączniaka; Signum 33 WG, przędziorka chmielowca; Nissorum Strong $250 \mathrm{SC}$ oraz inne szkodniki i patogeny zagrażające uprawie), obejmujące zarówno formy rodzicielskie, jak i mieszańce $\mathrm{F}_{1}$.

Dodatkowo, $\mathrm{z}$ roślin matecznych pobierano i wysadzano młode sadzonki rozłogowe celem utrzymania puli tych samych genotypów mieszańcowych, które następnie stanowiły materiał do doświadczeń fenotypowych.

\section{Material do badań molekularnych}

Izolacje genomowego DNA form rodzicielskich 'Elsanta' i 'Senga Sengana' oraz 200 roślin populacji mapującej przeprowadzono zgodnie z metodą opisaną przez Doyle i Doyle (1990). Tkankę liściową $(0,2 \mathrm{~g})$ ucierano w ciekłym azocie, zawieszano 
w buforze ekstrakcyjnym CTAB i inkubowano w temp. $65{ }^{\circ} \mathrm{C}$ przez 30 minut. W celu dokładnego odseparowania fazy wodnej (zawierającej kwasy nukleinowe) zawiesinę rozdrobnionej tkanki mieszano z równoważną ilością roztworu chloroform/alkohol izoamylowy $(24: 1 \mathrm{v} / \mathrm{v})$ i wirowano (15 000 g). Następnie uzyskane DNA wytrącano alkoholem izopropylowym $(1: 3 \mathrm{v} / \mathrm{v})$, suszono w temperaturze pokojowej i rozpuszczono w buforze TE. Cząsteczki RNA wytrawiano stosując RNazę A $\left(10 \mu \mathrm{g} \mathrm{ml}^{-1}, 37^{\circ} \mathrm{C} / 1 \mathrm{~h}\right)$. Czystość preparatów DNA oceniano na podstawie elektroforegramów w $0,9 \%$ żelu agarozowym oraz $\mathrm{w}$ oparciu o pomiar współczynników ekstynkcji próbki, przy długości fali 230, 260 i $280 \mathrm{~nm}$ (Gene Quant Pro Amersham Pharmacia Biotech). Koncentrację DNA w preparacie określano poprzez porównanie z DNA faga $\lambda$ o znanych stężeniach $\left(315,157\right.$ i $\left.79 \mathrm{ng}^{\mathrm{l}^{-1}}\right)$.

\section{Amplifikacja alleli polimorficznych (SSR-PCR)}

W oparciu o bazę sekwencyjną GDR (Genome Database for Rosaceae, ww.rosaceae.org) dla rodzaju Fragaria oraz na podstawie dostępnych danych literaturowych, zsyntetyzowano i przetestowano w reakcjach PCR, 450 par starterów mikrosatelitarnych.
Mieszanina reakcyjna $(13 \mu \mathrm{l})$ zawierała $5 \mathrm{ng}$ DNA - wyizolowane z odmian 'Elsanta' i 'Senga Sengana' oraz genotypów potomnych uzyskanych w wyniku ich krzyżowania, 0,325 U polimerazy (Ampli Taq, Applied Biosystems), $10 \times$ PCR-bufor II z 1,5 mM $\mathrm{MgCl}_{2}, 1,25 \mathrm{mM}$ dNTP (Applied Biosystems) i $0,35 \mu \mathrm{M}$ starterów SSR. Reakcje Touch-down PCR prowadzone były w zoptymalizowanych warunkach termicznych: $94^{\circ} \mathrm{C}-30 \mathrm{~s}$, $55^{\circ} \mathrm{C}-45 \mathrm{~s}, 72^{\circ} \mathrm{C}-60 \mathrm{~s} / 10$ cykli, $94^{\circ} \mathrm{C}-30 \mathrm{~s}$, $50^{\circ} \mathrm{C}-45 \mathrm{~s}, 72^{\circ} \mathrm{C}-60 \mathrm{~s} / 25$ cykli. Wygenerowane amplikony rozdzielano w 7\% żelach poliakrylamidowych, które następnie wizualizowano $\mathrm{w}$ świetle białym po wybarwieniu w $0,4 \%$ roztworze azotanu srebra.

\section{Określenie potożenia (loci) markerów}

Badania przeprowadzono na matrycach DNA wydzielonych $\mathrm{z}$ form rodzicielskich oraz z 200 roślin należących do populacji 'Elsanta' $\times$ 'Senga Sengana' o potwierdzonym statusie mieszańca. Do sporządzenia szkieletu mapy genomów obu odmian wytypowano zestaw markerów dostępnych w bazie danych (www.rosaceae.org) oraz opisanych dla map genetycznych dzikich gatunków $F$. nubicola, F. vesca oraz odmian 'Redgauntlet' i 'Hapil'.

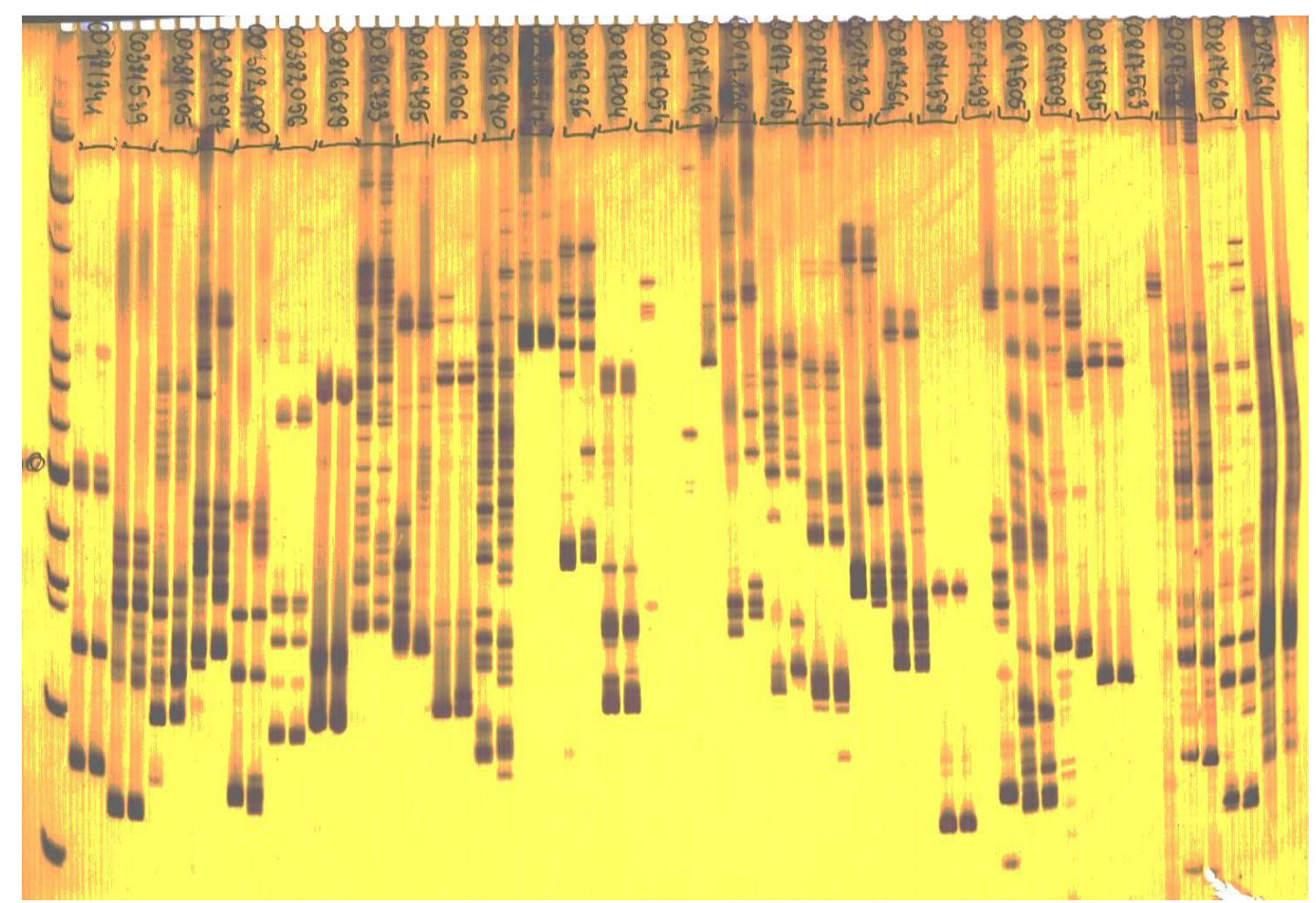

Rys. 1. Wzory prążkowe (reprezentują parę obu form rodzicileskich) przedstawiające wielkości alleli zidentyfikowanych dla 30 przkladowych markerów SSR, różnicujące genom odmiany 'Elsanta' (I ścieżka z pary) oraz 'Senga Sengana' (II ścieżka z pary).

Fig. 1. Band patterns (in pairs of both parental forms) representing the alleles identified for 30 SSR markers, differentiating the genome of 'Elsanta' (1st path from pair) and 'Senga Sengana' (2nd path from pair) cultivars. 
Amplifikację specyficznych fragmentów DNA prowadzono zgodnie $\mathrm{z} \mathrm{w} / \mathrm{w}$ procedurą.

Do sporządzenia 'szkieletu' mapy genetycznej 'Elsanta' $\times$ 'Senga Sengana' użyto 44 markerów SSR (ARFL002, ARSFL022, EMFn017, BFACT004, EMFn214, ARSFL011, FvH4180, FvH4153, FvH4164, FvH4160, FvH4154, ARSFL100, UDF009, BFACT017, BFFv09-11-02, EMFv018, CO816733, EMFv007, EMF132, FvH4163, BFACT045, FvH4169, BFACT036, UDF001, FvH4161, FvH4155, FvH4177, FvH4165, FvH4173, CFVC0316, BFACT002, ARSFL015, EMFn213, CFACT111, ARSFL012, CFVC015, BFACT003, FvH4171, COBRA, CO817054, BEFv14-29, EMFn049, FvC103. EMFn021).

Skład mieszaniny reakcyjnej oraz warunki reakcji touch-down PCR były takie same dla wszystkich par oligonukleotydów (temperatura annealingu w zakresie od $60^{\circ} \mathrm{C}$ do $55^{\circ} \mathrm{C}-10$ cykli, spadek temperatury $0,5^{\circ} \mathrm{C}$ na cykl), natomiast w przypadku markerów z grupy ARSFL, przez pierwsze 10 cykli temperatura malała $\mathrm{o} 0,5^{\circ} \mathrm{C}$ (z $55^{\circ} \mathrm{C}$ do $50^{\circ} \mathrm{C}$ ). Ostatecznie końcowe przyłączanie oligonukleotydów prowadzono w stałej temperaturze $55 \mathrm{i} 50^{\circ} \mathrm{C}$.

Szkielet mapy skonstruowano przy użyciu oprogramowania JoinMap v.3.0 (Biometrics, Kyazma NL) (van Ooijen i Voorrips 2001). Typ segregacji alleli badanych markerów genetycznych w populacji mapującej weryfikowano testem $\chi^{2}$ na podstawie wartości odchylenia pomiędzy ich rozkładem teoretycznym (mendlowskim) i obserwowanym. Przynależność markerów do poszczególnych grup sprzężeń określano na podstawie wartości progu LOD (Logarytm Odd Ratio) >3.0. Odległości mapowe zostały oszacowane przy użyciu funkcji mapującej Kosambi. Uzyskane grupy sprzężeń przedstawiono $\mathrm{w}$ formie graficznej, za pomocą z programu MapChart 2.1.

\section{Wyniki \\ Ocena stopnia heteryzotyczności genomów odmian 'Elsanta'i 'Senga Sengana'.}

W testach PCR, przeprowadzonych na matrycy DNA roślin 'Elsanta' i 'Senga Sengana' z 450 parami starterów mikrosatelitarnych, produkty polimorficzne uzyskano dla $228 \mathrm{z}$ nich (Tab. 1). Łącznie przeprowadzono 3532 reakcje SSR-PCR.

Wyniki amplifikacji fragmentów genomów uzyskanych na matrycy DNA z roślin 'Elsanta' i 'Senga Sengana' z 30 przykladowymi starterami mikrosatelitarnymi przedstawiono na poniższym elektroforogramie (Rys. 1). Wielkości zidentyfikowanych alleli polimorficznych, różnicujących formy rodzicielskie, oraz sekwencje zastosowanych do rekacji PCR oligonukleotydów zestawiono w tabeli 1.

Liczbę alleli heterozygotycznych zidentyfikowanych $\mathrm{w}$ genomach obu form rodzicielskich przedstawiono w tabeli 2.

Tabela 1

Table 1

Wielkości produktów różnicujących odmiany 'Elsanta' i ‘Senga Sengana' (allele segregujące) w reakcji SSR oraz sekwencje starterów generujących powyższe allele heterozygotyczne.

Sizes of PCR amplicons (segregating alleles) differentiating 'Elsanta' and 'Senga Sengana' genomes and the sequences of oligos generating the above heterozygous alleles.

\begin{tabular}{|c|c|c|c|c|c|}
\hline \multirow{2}{*}{$\begin{array}{l}\text { Lp. } \\
\text { No. }\end{array}$} & \multirow[t]{2}{*}{$\begin{array}{c}\text { Mrker } \\
\text { Mol. marker }\end{array}$} & \multicolumn{2}{|c|}{$\begin{array}{l}\text { produkty różnicujące (pz) } \\
\text { Size of the amplicons (pb) }\end{array}$} & \multirow{2}{*}{$\begin{array}{c}\text { starter F } \\
\text { Farward Primer }\end{array}$} & \multirow{2}{*}{$\begin{array}{c}\text { starter R } \\
\text { Revers Primer }\end{array}$} \\
\hline & & Elsanta & Senga Sengana & & \\
\hline 1 & FvH4004 & 480,600 & 300,560 & cccagatctccetacetttacc & agttctaccccettttcagacc \\
\hline 2 & FvH4005 & 270,275 & - & tcaagttacgtcgcttacatgg & ttgctgtttcaagaccactagc \\
\hline 3 & FvH4006 & 290,350 & 270,315 & cgagtactccaccttcaattcg & atgagagatcttccgtcgtagg \\
\hline 4 & FvH4009 & 480 & 450 & ttggctgttccagtttgaga & ccaaagggactggtggtaaa \\
\hline 5 & FvH4014 & 150,400 & 130,300 & tgacetcaatctcttgaacc & atcctactcaaaaccgtcagc \\
\hline 6 & FvH4019 & 200 & 220,600 & catctcagttggatcagaatcg & caaggaatcaaggatcataggc \\
\hline 7 & FvH4022 & - & $200,560,565$ & agttctggaacgtcctttaggc & acacaagcacatacccaaaacc \\
\hline 8 & FvH4023 & 595,600 & - & tactgggggcaatatgtttgg & gcccttgtaaacttctactgg \\
\hline 9 & FvH4025 & 260 & - & gttcagttgagagccataatgc & gaatgatgaaaggcagctaagg \\
\hline 10 & FvH4031 & 520 & - & tctcacctcatccaaatcttcc & agtgggaatggttcctttttgg \\
\hline 11 & FvH4033 & 150,190 & 110 & ctccacaaacctaataccaacg & gacgacgacttcttcaaaacg \\
\hline
\end{tabular}


Tabela 1 cd.

Table 1 cd.

Wielkości produktów różnicujących odmiany 'Elsanta’ i ‘Senga Sengana' (allele segregujące) w reakcji SSR oraz sekwencje starterów generujących powyższe allele heterozygotyczne.

Sizes of PCR amplicons (segregating alleles) differentiating 'Elsanta' and 'Senga Sengana' genomes and the sequences of oligos generating the above heterozygous alleles.

\begin{tabular}{|c|c|c|c|c|c|}
\hline \multirow{2}{*}{$\begin{array}{l}\text { Lp. } \\
\text { No. }\end{array}$} & \multirow[t]{2}{*}{$\begin{array}{c}\text { Mrker } \\
\text { Mol. marker }\end{array}$} & \multicolumn{2}{|c|}{$\begin{array}{l}\text { produkty różnicujące }(\mathrm{pz}) \\
\text { Size of the amplicons }(\mathrm{pb})\end{array}$} & \multirow{2}{*}{$\begin{array}{c}\text { starter F } \\
\text { Farward Primer }\end{array}$} & \multirow{2}{*}{$\begin{array}{c}\text { starter R } \\
\text { Revers Primer }\end{array}$} \\
\hline & & Elsanta & Senga Sengana & & \\
\hline 12 & FvH4041 & 200,250 & 220 & cagctgcatctatttgatctgg & cgagctcaactctcttctaccc \\
\hline 13 & FvH4042 & 280 & - & aacaggagcttatacggaatcg & aggagctcaatctcatcatcg \\
\hline 14 & FvH4049 & 250,260 & - & acggctactctagggaagatgg & ctctccaccetttgcattagc \\
\hline 15 & FvH4050 & 185,200 & 210 & tagcatccatagttccatacgc & caatacaatctcccaactcacc \\
\hline 16 & FvH4052 & 170,175 & 320 & caagaggtcgttaggtgaaatg & gtgttcaagcccagaaatgatg \\
\hline 17 & FvH4056 & - & 450 & gggggtattttgaagtgtaagc & gcgaaaaatatgagaggagagagg \\
\hline 18 & FvH4057 & $200,225,280,310$ & $235,240,300,380$ & agtttggaccgggtcaagagg & agctcttcctccetcacaacg \\
\hline 19 & FvH4058 & 220 & - & gttagagaagcagtggatgacg & gggcatctacacatgttgacc \\
\hline 20 & FvH4059 & 450 & - & tgcacatagagcaacagtataggg & ttgttagcatgaagtgcaaagc \\
\hline 21 & FvH4061 & - & 200 & accaactccatactccacaagc & gectccetctctagctcttcc \\
\hline 22 & FvH4082 & - & 495 & cggtttacctaactccaactgc & cctgcaagaaatctctactgtcg \\
\hline 23 & FvH4083 & 360,600 & 300,470 & aattgggggtgtgacaatgc & gcttcaaatttgggatctgg \\
\hline 24 & FvH4086 & - & 600 & acaccccaagcaaattacagg & tgctatttaggcaactccttcc \\
\hline 25 & FvH4088 & - & 400,450 & cctcagtcttaacgaacgaacc & tagagagagcaccgactcaagg \\
\hline 26 & FvH4090 & 320 & 330 & cagttgatgtgttgctgagtcc & agtttttgttttcatcttttgg \\
\hline 27 & FvH4091 & $220,300,400$ & 200 & tcaccggttccttctttatagc & taatttcttgcaggacgttcg \\
\hline 28 & FvH4102 & 600 & 610 & tttccttttggttgaaaactcc & tcataggaagcttttattcatacc \\
\hline 29 & FvH4104 & 240,250 & 510 & agactgctcatcctctctttgc & atcatgggagagaacattaggg \\
\hline 30 & FvH4105 & - & 320,330 & cgttggagatctggtaaactcc & taaccttccectcgtgaaatcc \\
\hline 31 & FvH4106 & 155,215 & 220 & tacaaaggacttgcctcttagg & tcactttcgttgtcctacatcc \\
\hline 32 & FvH4112 & $265,320,330$ & 210,460 & tttcaacaaattaaggcaaacg & gccatagaaaaccagaaaaacc \\
\hline 33 & FvH4113 & 125 & 110 & tgactagcaatagtgcaacagc & cggcagagaacccagtaagc \\
\hline 34 & FvH4114 & $200,380,400$ & - & gcagcatgagagacaagatgc & gttagcagaagggaaatgaacc \\
\hline 35 & FvH4116 & 290,405 & 380 & ggacattgaccaagcatttacg & tacggtcaggaagattgagacc \\
\hline 36 & FvH4117 & 295,305 & 300 & actttgcttggctagttgtcg & gagggttctggagtctaagtgc \\
\hline 37 & FvH4121 & 400 & - & tacacagtgacatagccgatgc & gtcctaggtttcctcgttctcc \\
\hline 38 & FvH4123 & 240 & 245 & gttgaagcaaccttgaatgc & ggaggacaactccaatttatgg \\
\hline 39 & FvH4124 & 240,285 & 385 & gcacagttccatcagtttttca & acaattgatccettggaaattg \\
\hline 40 & FvH4127 & $180,200,385$ & $170,195,485$ & accaccacaacctagtctctgc & tccetaagttttctctccatcc \\
\hline 41 & FvH4131 & 135 & - & cagactcagcagagtgatttgg & ctaatggeccgtatcttctcc \\
\hline 42 & FvH4134 & 100 & - & aagtgaaggaggggaagaagg & gcttcataaaacagccactgc \\
\hline 43 & FvH4136 & $190,580,600$ & - & ttcctgatcaagctaggaatgc & ccttggtgtactctcaaactcg \\
\hline 44 & FvH4145 & $205,280,410$ & 300,420 & aaagtcttgggggagtaaaagg & ggtacatggtgatgtgtcatcc \\
\hline 45 & ChFaM 149 & - & $165,595,600$ & ccctcttccegtaaagtcca & cggactcaccggtcactaga \\
\hline 46 & $\mathrm{ChFaM} 262$ & 400 & - & actcggtgaggaaagacgaa & agagaagaccgctgaggatg \\
\hline 47 & ChFvM 232 & 320 & 330 & gcttcttgggacagcaacac & tgaaccetgcatttcctctg \\
\hline 48 & ChFvM 243 & 330 & 340 & tcctttctcgctcactgtca & aaacaaaggaaaggctggtg \\
\hline 49 & ChFvM 245 & - & 510 & tcaaccacaccgetactcct & cttgctgagctcgtccttgt \\
\hline 50 & ChFaM 009 & 410 & - & tccaagttccagagctcctt & cgtcgagctcagacatgaaa \\
\hline 51 & ChFaM 010 & 200,580 & 210 & tatcgectgcaattcatctg & gctggctctgtggagtgagt \\
\hline 52 & ChFaM 011 & $95,300,360$ & $80,90,210,270$ & tcctctcettctttccettca & cgagatctcccgagactgag \\
\hline 53 & ChFaM 017 & $\begin{array}{c}80,90,160,250 \\
295\end{array}$ & 415 & ctcactctctgcgaacttgc & caactcaccttgcaccgatt \\
\hline
\end{tabular}


Tabela 1 cd.

Table 1 cd.

Wielkości produktów różnicujących odmiany 'Elsanta’ i ‘Senga Sengana' (allele segregujące) w reakcji SSR oraz sekwencje starterów generujących powyższe allele heterozygotyczne.

Sizes of PCR amplicons (segregating alleles) differentiating 'Elsanta' and 'Senga Sengana' genomes and the sequences of oligos generating the above heterozygous alleles.

\begin{tabular}{|c|c|c|c|c|c|}
\hline \multirow{2}{*}{$\begin{array}{l}\text { Lp. } \\
\text { No. }\end{array}$} & \multirow[t]{2}{*}{$\begin{array}{c}\text { Mrker } \\
\text { Mol. marker }\end{array}$} & \multicolumn{2}{|c|}{$\begin{array}{l}\text { produkty różnicujące (pz) } \\
\text { Size of the amplicons }(\mathrm{pb})\end{array}$} & \multirow{2}{*}{$\begin{array}{c}\text { starter F } \\
\text { Farward Primer }\end{array}$} & \multirow{2}{*}{$\begin{array}{c}\text { starter R } \\
\text { Revers Primer }\end{array}$} \\
\hline & & Elsanta & Senga Sengana & & \\
\hline 54 & ChFaM 022 & $185,200,495$ & - & gggecactcctacttcttca & ttggecttgagagcttcgat \\
\hline 55 & ChFaM 026 & 100 & - & tcgtctctcgtttctctaaaagc & atcaagtgetcgtccacgta \\
\hline 56 & ChFaM 030 & 300,335 & - & ccatgaagcagtgaagtcca & agaaaatcccgagagccttt \\
\hline 57 & ChFaM 031 & 300,310 & 200,210 & gctagcaaagccctaagcaa & acggtgggcacacttaaaga \\
\hline 58 & ChFaM 032 & - & 410 & ggtccetgettcttcttcttt & ttcagccccattttccagta \\
\hline 59 & ChFaM 033 & 110,505 & 115,510 & cacaaatccacacacagcag & cccaggaaggtaaccacaaa \\
\hline 60 & ChFaM 036 & 130 & 135 & gcagcctcaagaagtgaagg & ccatcttgatatcacaggcataa \\
\hline 61 & ChFaM 037 & 505 & - & acgacgatcaccacaaggac & aagctccgtcgtttcetctt \\
\hline 62 & ChFaM 040 & - & 205,300 & agtggtcatcagcaccatca & taaccgggaacggtactctg \\
\hline 63 & ChFaM 041 & 185 & $180,280,490$ & ccacacgaaggagaaggaga & aacgtgtcattcgaccacaa \\
\hline 64 & ChFaM 044 & 170,615 & $165,310,410,595$ & cgctgagtcgttctaatttca & ttttgttgacgagcgagatg \\
\hline 65 & ChFaM 046 & $195,300,310$ & - & ccatttccatggecttgttt & ggccttgttgggtctgagag \\
\hline 66 & ChFaM 047 & 235 & $200,215,240,260$ & tcatttctctctcccetcgat & gatgtgatttacggcgaagg \\
\hline 67 & ChFaM 056 & 195,260 & $265,510,600$ & aaaacgtcgtcgttcaggat & cgtactgctgttgctgctgt \\
\hline 68 & ChFaM 058 & $\begin{array}{c}140,195,205,210 \\
300,420,500\end{array}$ & $550,560,580$ & gacccaaacacacctgaac & ctccccattctgggaaatct \\
\hline 69 & ChFaM 060 & $165,550,560,580$ & $280,590,610$ & tgagctaccaccaagaaccc & aataccettggtaccectcg \\
\hline 70 & ChFaM 063 & 120,300 & 125,195 & gacgtctccgatccgttgat & ctggctcgcgtacgactttc \\
\hline 71 & ChFaM 064 & 285 & 190,280 & caccaacttcgacaacctca & gactcttctttggegagctg \\
\hline 72 & ChFaM 065 & $220,245,250,265$ & 200,250 & gaccgggagagataacagca & atagaagccaatgcgtgatg \\
\hline 73 & ChFaM 066 & 110,590 & $115,280,310,580$ & attttggccacgaagaattg & cgatgtcaggaacgaactga \\
\hline 74 & ChFaM 068 & 420 & 200,425 & catctccagttccttggetc & acgaccattcctcttcctca \\
\hline 75 & ChFaM 070 & 280,630 & - & agcattgaattcccagttttg & ccttgcagcaggaactaagg \\
\hline 76 & ChFaM 072 & 385 & - & tggcagaaatttccaaaagg & ctcccccagaagtccagatt \\
\hline 77 & ChFaM 077 & $250,320,400,440$ & $270,300,395,410$ & gaaagggctggacatggata & atgttgttatttggcetgct \\
\hline 78 & ChFaM 078 & $\begin{array}{c}245,285,290,300 \\
315,390,410\end{array}$ & 235 & cagcctcattgcaaatctga & cttaccggtttcgatgtggt \\
\hline 79 & ChFaM 080 & 530,560 & 160,540 & ttcggtgccggtaaagatac & aagttccaccaccatgcaat \\
\hline 80 & ChFaM 081 & - & $\begin{array}{l}295,300,310 \\
\quad 340,415\end{array}$ & aactgagctctcggcaagtc & gaatactcgcggaggaagtg \\
\hline 81 & ChFaM 082 & 230,235 & 220,245 & agtacggcaattgaagctcg & gatctcggttgaagatcgga \\
\hline 82 & ChFaM 083 & 220,250 & - & ttttctggcttttggattgg & gcactttttcatcacaggca \\
\hline 83 & ChFaM 086 & 280 & 225 & tttggagctcaatcccatctg & atttggecagcetccgtct \\
\hline 84 & ChFaM 088 & 660 & 140 & ggtggcaaaactcatggaga & gggaagcgaagttgaagagg \\
\hline 85 & ChFaM 092 & 110 & - & acccaagttccettcgactc & atgcgetttgcataacaggt \\
\hline 86 & ChFaM 093 & $\begin{array}{c}285,290,300,390, \\
395\end{array}$ & - & cgccctcaaatccetctaac & gaagtgagtgttccgctgct \\
\hline 87 & ChFaM 094 & 180 & 175,185 & atggagggcgctactgaaaa & aatggcgagcttggactttc \\
\hline 88 & ChFaM 095 & 210 & - & gccagaagcaaaaaccagaa & gggaagttgaaattgtcgga \\
\hline 89 & ChFaM 097 & $\begin{array}{c}275,325,250,400 \\
450,470\end{array}$ & 265 & gccaaaggttggttctttga & gccattttggaagaggtgaa \\
\hline 90 & ChFaM 098 & $305,495,520$ & 205,215 & gtgagagtcagcccacceta & gcgacgaggatgaagaagag \\
\hline 91 & ChFaM 100 & 100,170 & 120,190 & ttggaacccagaaaatcgaa & cagcggagagagaaacaagg \\
\hline 92 & ChFaM 101 & 150,500 & $220,240,520$ & ggagtaagctgatcactctgt & actccgaggetgtaatccet \\
\hline
\end{tabular}


Tabela 1 cd.

Table 1 cd.

Wielkości produktów różnicujących odmiany 'Elsanta' i ‘Senga Sengana' (allele segregujące) w reakcji SSR oraz sekwencje starterów generujących powyższe allele heterozygotyczne.

Sizes of PCR amplicons (segregating alleles) differentiating 'Elsanta' and 'Senga Sengana' genomes and the sequences of oligos generating the above heterozygous alleles.

\begin{tabular}{|c|c|c|c|c|c|}
\hline \multirow{2}{*}{$\begin{array}{l}\text { Lp. } \\
\text { No. }\end{array}$} & \multirow[t]{2}{*}{$\begin{array}{c}\text { Mrker } \\
\text { Mol. marker }\end{array}$} & \multicolumn{2}{|c|}{$\begin{array}{l}\text { produkty różnicujące (pz) } \\
\text { Size of the amplicons }(\mathrm{pb})\end{array}$} & \multirow{2}{*}{$\begin{array}{c}\text { starter F } \\
\text { Farward Primer }\end{array}$} & \multirow{2}{*}{$\begin{array}{c}\text { starter R } \\
\text { Revers Primer }\end{array}$} \\
\hline & & Elsanta & Senga Sengana & & \\
\hline 93 & ChFaM 105 & 170,180 & 160,175 & cctccaaacacaatccacca & tctgaggtttatgcgggact \\
\hline 94 & ChFaM 106 & $170,190,230,335$ & 120,410 & accaaccgaggcgagagag & cgtcatctgcacctgettc \\
\hline 95 & ChFaM 107 & - & 500 & tgccaaacaaacaaatgttga & catatcgatgtccttcataggg \\
\hline 96 & ChFaM 108 & 520 & 170 & catggaaagagagcgaaagc & cgaggaatgagggaggaatc \\
\hline 97 & ChFaM 109 & - & 420,450 & aagctgcttgcgaagaacaa & ggctgatgccagtccattta \\
\hline 98 & ChFaM 110 & $310,605,615$ & - & ttttcctttggtggttttgg & ccagagaaagccatttaggc \\
\hline 99 & ChFaM 111 & 145,180 & 135 & gcccaaccgagtctctctct & cgggcttcaatttgctcaat \\
\hline 100 & ChFaM 112 & 495 & 485 & ttcaagcttttcttcttcctctc & catcttcacctgaccectct \\
\hline 101 & ChFaM 114 & - & $145,275,495$ & tgtggtgcettggtttacaa & cgectctctcetctctaatcc \\
\hline 102 & ChFaM 115 & 460,480 & 280,285 & cctcggettcttcatctttg & accacactgacaggacgatg \\
\hline 103 & ChFaM 120 & $130,200,210,420$ & $255,300,320,330$ & ggtttcatcagagggcgtctt & taaagctcccagcaggcatt \\
\hline 104 & ChFaM 122 & $245,255,260$ & - & gactcacagtctctcccagtgt & tgatattgagcaacgggtga \\
\hline 105 & ChFaM 126 & 270 & - & gttagggagtccgggaatga & ttccaatcccatctgacgac \\
\hline 106 & ChFaM 129 & 195 & - & agatcaacatcgectccaac & tgctcgttgtccataacctg \\
\hline 107 & ChFaM 130 & $240,260,300$ & 195,310 & gccagtcacaagaagccaaa & tgctctgaaaccctttatctg \\
\hline 108 & ChFaM 144 & 390 & - & cacgtcttggettcctcttc & cggagcagattttcttggag \\
\hline 109 & ChFaM 146 & 170 & 150,155 & acgagggaagaatggagcac & agatggtcctgactggatgg \\
\hline 110 & ChFaM 147 & 350,360 & - & acgagggtcacctgagactg & ccaggagaaggtaccgaagg \\
\hline 111 & ChFaM 148 & - & 210 & ccctccatcaaagccagtt & cattagaccccgacttgtca \\
\hline 112 & ChFaM 151 & 200 & - & accaccaccgttttctcctc & accaccgactcgtcettctt \\
\hline 113 & ChFaM 159 & 285 & - & tctctctcatcgecccagag & acccatccacagggttcttg \\
\hline 114 & ChFaM 160 & - & 300,480 & ccactccccaaaagagcaca & ctgcetccacaatcctcacc \\
\hline 115 & ChFaM 161 & $210,510,615$ & 270 & cgaggccttgtcttctttgt & gcggaggtagctgttgtagc \\
\hline 116 & ChFaM 163 & 150,265 & 155 & ttcgggtcttgtattgctttga & ttcaattccgaaggcacaac \\
\hline 117 & ChFaM 164 & 235 & 200 & cactcagccagatccagagc & gcgccaaggatggtcttaat \\
\hline 118 & ChFaM 174 & 140,175 & 160,195 & gagggagatggcacggagat & ctccggcattgaaatcgaga \\
\hline 119 & ChFaM 177 & $245,265,400$ & - & cctgcagagtgcaagagaga & cactcacaaggcatgagagcta \\
\hline 120 & ChFaM 178 & $165,280,325$ & 320 & aaacgaagaaaggaagtcttcaa & agctgtgcaggggtttatgt \\
\hline 121 & ChFaM 194 & - & 175,195 & cccttcettgecagtcattt & cccatcccacagttgttctc \\
\hline 122 & ChFaM 196 & - & 305 & cctctcacctctttctctctaaaa & agcgcatgagtctgctgtta \\
\hline 123 & ChFaM 203 & 480 & - & cgagggtcacggctactaaa & tgagtatgaccaatccgaaaga \\
\hline 124 & ChFaM 209 & - & 295 & cccccaaaaccctctattct & atcattcccaagccactgtc \\
\hline 125 & ChFvM 028 & 168,505 & 170,507 & aatggcatcaacttctgcac & cagcctgetgctgtagttct \\
\hline 126 & ChFvM 049 & - & 500,505 & atggttggtgatcaatggtg & ttcatatgcaatttgatggaac \\
\hline 127 & ChFvM 087 & 280,295 & 300 & gaaaggggaagccttttcat & tgggacgaaagttcccaata \\
\hline 128 & ChFvM 125 & - & 150,520 & gcgactgccatcgtaaccta & tctccaatgttttcgccaag \\
\hline 129 & ChFvM 140 & - & 185 & ccacttcccataccactgga & cgtcgtaggttcggtctctg \\
\hline 130 & ChFvM 181 & 175 & 155,165 & ggagaactgctttggtaggg & acgtacaccagcagatgagc \\
\hline 131 & ChFvM 182 & $400,435,515$ & 470 & ggaaccaaacgaacaccaac & gcggaggagtgagtgaagac \\
\hline 132 & ChFvM 184 & 255 & $\begin{array}{l}235,240,340 \\
350,600\end{array}$ & gcactttggggttttgggta & ttgcaagaaccccettccta \\
\hline 133 & ChFvM 191 & 245,535 & $255,285,300,350$ & ccagcagaatcctcaaatgc & gtgccaacaagcccattg \\
\hline 134 & ChFvM 192 & - & $265,275,450$ & tgaggtcagtctgtgagaattg & tttccgagagtggagagcat \\
\hline
\end{tabular}


Tabela 1 cd.

Table $1 \mathrm{~cd}$.

Wielkości produktów różnicujących odmiany 'Elsanta' i ‘Senga Sengana' (allele segregujące) w reakcji SSR oraz sekwencje starterów generujących powyższe allele heterozygotyczne.

Sizes of PCR amplicons (segregating alleles) differentiating 'Elsanta' and 'Senga Sengana' genomes and the sequences of oligos generating the above heterozygous alleles.

\begin{tabular}{|c|c|c|c|c|c|}
\hline \multirow{2}{*}{$\begin{array}{l}\text { Lp. } \\
\text { No. }\end{array}$} & \multirow[t]{2}{*}{$\begin{array}{c}\text { Mrker } \\
\text { Mol. marker }\end{array}$} & \multicolumn{2}{|c|}{$\begin{array}{l}\text { produkty różnicujące (pz) } \\
\text { Size of the amplicons }(\mathrm{pb})\end{array}$} & \multirow{2}{*}{$\begin{array}{c}\text { starter F } \\
\text { Farward Primer }\end{array}$} & \multirow{2}{*}{$\begin{array}{c}\text { starter R } \\
\text { Revers Primer }\end{array}$} \\
\hline & & Elsanta & Senga Sengana & & \\
\hline 135 & ChFvM 193 & - & 140 & catcagaaccatcaatcatcg & tactgccggagaatgaaca \\
\hline 136 & ChFvM 201 & - & $245,285,325,335$ & tgattcaactccagcgaagc & atcagcaggcgaatccttct \\
\hline 137 & ChFvM 202 & 225,235 & - & caaagggctccagctatctc & aggatcgtcagctaagaagca \\
\hline 138 & ChFvM 205 & 220 & 125,185 & gcgaaaccetatggattgtt & acaaccaccaaattcccatt \\
\hline 139 & ChFvM 210 & - & $185,265,540$ & tccccacattttccttgttt & gtggtgttggtgagtggaga \\
\hline 140 & ChFvM 212 & $150,170,190$ & 195 & caaatcttcaacggtctctcc & acggaggaggaggaagtcat \\
\hline 141 & ChFvM 213 & $\begin{array}{c}195,245,330,350, \\
450\end{array}$ & 280 & aaccctaggaggctgaaacc & ataccccgggtggtacttgt \\
\hline 142 & AW06432 & $\begin{array}{c}250,270,280,500, \\
570\end{array}$ & - & tgagctgaagaaggtgctga & aagggaaactggaggtagcaa \\
\hline 143 & CO378933 & 150,500 & - & cgaggcttgtctctgtgttg & cacgaccttgacaccettct \\
\hline 144 & CO379009 & 105 & - & tgtgattgggagagaggagg & ctgccccaaacttggtttta \\
\hline 145 & $\mathrm{CO} 379012$ & - & 145 & cacgaggattgtttgaaccc & accaacacacaaagctgctg \\
\hline 146 & CO379659 & 250,400 & 140,200 & aggggaggcctcacttagag & tatccatgagatcccagcet \\
\hline 147 & CO380151 & - & 150 & cgagggtttgatcgagtctg & aacatgatcacaaggccaca \\
\hline 148 & CO381174 & 275 & 445,455 & ccacaagaaaggagacgagc & tcaggagcatgaatcaatcg \\
\hline 149 & CO381539 & 272 & 270,265 & gtctgeccetgttacgctac & ctgtgtagctccggcacata \\
\hline 150 & CO381605 & - & 300 & ccacccetttacctttcaca & caattccgaaggcacaactt \\
\hline 151 & CO381897 & 230 & - & agaggctgaggatcatggtg & ggcaaatacaatgctaaacca \\
\hline 152 & CO382008 & - & $125,145,385$ & gccettgcttagttgctttg & atgcatggctatggcttgtt \\
\hline 153 & CO816733 & $\begin{array}{c}275,300,400,480, \\
570\end{array}$ & 310,350 & tcccaacacctcacttgtcc & attcagccaggtctgagcat \\
\hline 154 & CO816806 & - & 205 & cgagggagaaaccctaacct & ggacgatccettgtagtgga \\
\hline 155 & CO816840 & 270,340 & $150,215,295,305$ & cagcettgatgtctcgttga & ccatgacatcctctgecttt \\
\hline 156 & CO816936 & 300 & 380,520 & ttctctccgatcttctccga & catcgactggettctcettc \\
\hline 157 & CO817004 & 220,240 & 225 & cgtcagccctaagaagatgg & acgaccaatacagaccaggg \\
\hline 158 & CO817138 & 250 & $285,500,590$ & tgaaaacttttgctctgggc & tcaggccatgaaacactctg \\
\hline 159 & CO817185B & $195,400,510,565$ & 260,500 & tcatccactgggaagaaagg & catcaatcatgcacacacga \\
\hline 160 & CO817242 & - & $150,520,525$ & aatccccaaatcctcaaacc & ctccacgctcttcttgttcc \\
\hline 161 & CO817330 & - & $\begin{array}{l}270,405,430 \\
505,510,550\end{array}$ & gcttcatggcttcgttcttc & gtggcattcagttgggctat \\
\hline 162 & $\mathrm{CO} 817364$ & 285,295 & 260 & gecttcccettcttcaaatc & gtccattttccagtggtgct \\
\hline 163 & CO817505 & 120,280 & - & tcctgaagcaacgatgactg & cacttgccgcagaagaaaa \\
\hline 164 & CO817509 & $130,140,195$ & 215 & tcaccgtcctccttctcaac & cgaagaggaaattgagccag \\
\hline 165 & CO817772 & - & 500 & tcacaaccgacgagtttcag & tttcttcactgecetgetct \\
\hline 166 & CO817850 & - & 300 & gtgttgagcaagaatggggt & tagtgcccagaatgaggett \\
\hline 167 & CO817919 & 270,280 & - & cagaatccaccggcttacat & cgctagcttttctgctcgat \\
\hline 168 & CO818131 & 250,315 & 295 & ccttcetccgaaacctact & gggctcaggttatacgagca \\
\hline 169 & CX661091 & 180 & 235 & aagccatgactacctccacg & atgaagccgaaatcgaaatg \\
\hline 170 & CX661274 & - & 215 & tataacaacgttgggecctc & tacgccagctcataccacag \\
\hline 171 & CX661428B & 295,330 & - & gaagacggtggatgaggtgt & ctgctgaaacccgaatccta \\
\hline 172 & CX661749 & - & 500 & tagatttttcceattcecec & atctgacccaacaaaaccca \\
\hline 173 & CX661752 & - & 165,175 & acctgacctgaccaaaccag & tggggatgaggatgagagtc \\
\hline 174 & CX661843 & 245,515 & - & ctcccatagatgcctcgaac & ttgaacagcgagaagtggtg \\
\hline
\end{tabular}


Tabela 1 cd.

Table $1 \mathrm{~cd}$.

Wielkości produktów różnicujących odmiany 'Elsanta' i ‘Senga Sengana' (allele segregujące) w reakcji SSR oraz sekwencje starterów generujących powyższe allele heterozygotyczne.

Sizes of PCR amplicons (segregating alleles) differentiating 'Elsanta' and 'Senga Sengana' genomes and the sequences of oligos generating the above heterozygous alleles.

\begin{tabular}{|c|c|c|c|c|c|}
\hline \multirow{2}{*}{$\begin{array}{l}\text { Lp. } \\
\text { No. }\end{array}$} & \multirow[t]{2}{*}{$\begin{array}{c}\text { Mrker } \\
\text { Mol. marker }\end{array}$} & \multicolumn{2}{|c|}{$\begin{array}{l}\text { produkty różnicujące (pz) } \\
\text { Size of the amplicons }(\mathrm{pb})\end{array}$} & \multirow{2}{*}{$\begin{array}{c}\text { starter F } \\
\text { Farward Primer }\end{array}$} & \multirow{2}{*}{$\begin{array}{c}\text { starter R } \\
\text { Revers Primer }\end{array}$} \\
\hline & & Elsanta & Senga Sengana & & \\
\hline 175 & CX661893 & - & 190,610 & cgggttcttctacttcgtcg & gcccaaagacaggcctagat \\
\hline 176 & CX661895A & 100 & - & gtagccatggaatcgtccac & actgcgagcaagtgtcttga \\
\hline 177 & CX662065 & 170,495 & - & acagagagccagaaacggaa & agcgagagagagagcgaatg \\
\hline 178 & CX662065A & - & $190,235,360,500$ & atgaccacagcaacctctcc & gcgtgtttgggattgagact \\
\hline 179 & CX662153 & $115,120,175$ & 130 & gaaactcccccgaatttacg & tctcgggtgagctgagaaat \\
\hline 180 & CX662162 & 290,505 & - & tcaccacatgaaaagttgcc & atagaaagagcggcacgaaa \\
\hline 181 & CX662184 & 155 & 145,160 & acgetcttctttcactccca & gagagagatgtgcggagagg \\
\hline 182 & CX662207 & $265,285,290$ & 310 & agcagccggtcagatgatag & atcacggtcaaagccaactc \\
\hline 183 & CX662235 & $220,255,340,345$ & - & cctctcttcccacactcaa & gtagctctttccgaacgtgg \\
\hline 184 & FvA 108 & 150 & - & acaaagagaccaccaactacc & gatagccaaaagagcagtga \\
\hline 185 & FvA 110 & 185,245 & 255,265 & caacctttcctagcatcaactc & actcgatctgaaatcgttgtct \\
\hline 186 & FvA 114 & $120,270,315$ & 150,295 & attggctaatgaatctccg & ggcaagggaatggataata \\
\hline 187 & FvA 115 & $98,370,450$ & 100,445 & acaagttcgcagggtatga & gggaaaacacagaaatctcc \\
\hline 188 & FvA 117 & 110,295 & - & ccattttacattgtcacaacg & gttagggtttcatgtggactc \\
\hline 189 & FvA 119 & 280,400 & $120,150,265$ & gccettgatgacagaaaag & cccttcgttggagataatg \\
\hline 190 & FvA 123 & - & 310 & gcaatgttgttactgaaatgtg & agcatctcttagtgectcatc \\
\hline 191 & FvA 125 & 420 & - & atccaagggctaagagagg & cagaaatacccaccaaagttc \\
\hline 192 & FvA 127 & 95,215 & 195 & tctccetcatccacaatcaac & accggagtgaaaccctaattc \\
\hline 193 & FvA 129 & 145 & - & gaaaggagtctgttttgtgtcc & actgggctcatcatacgc \\
\hline 194 & FvA 2 & 250,270 & 252,262 & gttccatcacttacagacatcc & cctgattatgtgectttattc \\
\hline 195 & FvA 5 & 120 & 85,135 & aagggagagaagagagaaagtg & acaacctatcggctcattaac \\
\hline 196 & FvA 7 & - & 550 & cagtgaagacttccgcactag & gcatatcgtcattatgtgc \\
\hline 197 & FvA 9 & 570,580 & 610 & gaggtgctccttgtgaatg & aacccatcaaccagtttgg \\
\hline 198 & FvB 1 & $290,315,450,480$ & 620 & agagcagaagaaaaccatagc & cctccetggaaatagatacac \\
\hline 199 & FvB 101 & $175,195,480,485$ & 120 & tcaagtctcgaccaaaataact & cgttgtcacttccattagagg \\
\hline 200 & FvB 108 & $300,455,495$ & 130,215 & ggttgacatgagtgcatattc & gaaggtataggagtgcaaagtg \\
\hline 201 & FvB 110 & 215,225 & - & ctaccgcaccataatttagaag & catccaaatgaacctattcaag \\
\hline 202 & FvB 111 & $270,275,280,520$ & 190,195 & ttaggttttgcgaagttgaag & aggagaaccgcgctagtg \\
\hline 203 & FvB 112 & $\begin{array}{c}165,195,205,285, \\
600\end{array}$ & $290,335,250$ & ggcaacgaagagtaaggc & caaccataataccctcattttc \\
\hline 204 & FvB 113 & - & 230 & tgacccagaaatgaaagaagg & agaaagaacctgctgcttgag \\
\hline 205 & FvB 116 & 200 & 215,225 & cetccatccetaactttcc & getctttgtcttcgtcagc \\
\hline 206 & FvB 119 & 330,385 & 380,390 & acccattgccatccetact & ccacctgaacaaccaccac \\
\hline 207 & FvB 120 & 220,240 & - & ataccetcatctcttgctcttg & gattcttcatgtgatcgtctga \\
\hline 208 & FvB 123 & - & $360,370,390$ & gaaacacttttgccettgtg & ggtttactgggggtcag \\
\hline 209 & FvB 124 & $190,220,250,260$ & 205,240 & agacaaacaagcagcaatagtg & agaaagggaagtgcctaagtg \\
\hline 210 & FvB 126 & 125 & 110,180 & gagcatcggcactacacc & catggctggcttcagatc \\
\hline 211 & FvB 127 & 420,500 & 265,270 & tttcaaggcaaatccactatc & gcatcggaagcatcaagt \\
\hline 212 & FvB 129 & 510,550 & - & gcgatgaaacagtagcagc & gaagaaggggggaagaatc \\
\hline 213 & FvB 132 & 220,250 & 260 & aaggetccccetgtttag & gaacctgtaggctgtgtagaaa \\
\hline 214 & FvB 2 & $230,340,350$ & 600 & ttgaggcacttgaaaaaagac & aagggaggtggaaaggtg \\
\hline 215 & FvB 8 & $280,300,400,420$ & $275,290,320,410$ & ggtgagtggtatttgcctaac & cttcattacggtggagtctg \\
\hline
\end{tabular}


Tabela 1 cd.

Table 1 cd.

Wielkości produktów różnicujących odmiany 'Elsanta’ i ‘Senga Sengana' (allele segregujące) w reakcji SSR oraz sekwencje starterów generujących powyższe allele heterozygotyczne.

Sizes of PCR amplicons (segregating alleles) differentiating 'Elsanta' and 'Senga Sengana' genomes and the sequences of oligos generating the above heterozygous alleles.

\begin{tabular}{|c|c|c|c|c|c|}
\hline \multirow{2}{*}{$\begin{array}{l}\text { Lp. } \\
\text { No. }\end{array}$} & \multirow[t]{2}{*}{$\begin{array}{c}\text { Mrker } \\
\text { Mol. marker }\end{array}$} & \multicolumn{2}{|c|}{$\begin{array}{l}\text { produkty różnicujące (pz) } \\
\text { Size of the amplicons (pb) }\end{array}$} & \multirow{2}{*}{$\begin{array}{c}\text { starter F } \\
\text { Farward Primer }\end{array}$} & \multirow{2}{*}{$\begin{array}{c}\text { starter R } \\
\text { Revers Primer }\end{array}$} \\
\hline & & Elsanta & Senga Sengana & & \\
\hline 216 & FvC 10 & $295,350,380$ & $255,285,300,460$ & cetccatgtegatcetcttatc & gccaattccgattattcttgag \\
\hline 217 & FvC 103 & $200,215,250,395$ & - & tcctccaactccaacttctc & cgaatctatgtccectatcg \\
\hline 218 & FvC 105 & 270,350 & - & gggtggtcaagtctccag & actccgattactgttttccag \\
\hline 219 & FvC 107 & 205,480 & 180 & ggcaaattacatgatgaaccag & gaatggagtccttggagaactc \\
\hline 220 & FvC 108 & 275 & $345,255,495$ & tcccgtgaacagtgtcag & agcaaagaggtagagaacgag \\
\hline 221 & FvC 109 & $165,210,520,590$ & 260 & agggcgagacttgaaatatg & aagccttacctggaaattacc \\
\hline 222 & FvC 110 & 420 & 450 & ctgtttcttcctcagattgttc & gtcattgtaactgctgtgtg \\
\hline 223 & FvC 111 & $\begin{array}{c}215,260,270,290, \\
340,415\end{array}$ & $200,240,315,400$ & ccattcttcgeccettaac & caaaactgtcactgcctcaaa \\
\hline 224 & FvC 112 & $145,160,170$ & $147,150,280$ & ggtacgaattgtgggaattg & cggectgattgtattatctg \\
\hline 225 & FvC 113 & $220,250,260,270$ & 180 & ccetcetctctttctetttcc & ggcagacagatccgaga \\
\hline 226 & FvC 12 & - & 190,250 & ggaggacagcgatagagatatg & gggtccatttctgtttaacaac \\
\hline 227 & FvC 122 & 320,385 & 300 & tcttcatacccatacccactac & ccagacacccatctaattctac \\
\hline 228 & FvC 123 & 170 & 140,250 & gaccacaaacccactaatc & caaacaccgagacttctgag \\
\hline
\end{tabular}

Liczba produktów SSR-PCR różnicujących genomy odmian 'Elsanta' i 'Senga Sengana'.

Number of SSR-PCR products differentiating 'Elsanta' and 'Senga Sengan' genomes.

\begin{tabular}{|c|c|c|c|c|}
\hline \multirow{2}{*}{$\begin{array}{l}\text { Grupa starterów } \\
\text { Group o teste } \\
\text { markers }\end{array}$} & \multirow{2}{*}{$\begin{array}{l}\text { liczba par starterów testowa- } \\
\text { nych z danej grupy } \\
\text { Number of primer pairs test- } \\
\text { ed from the merker group }\end{array}$} & \multirow{2}{*}{$\begin{array}{l}\text { liczba starterów w grupie, w reakcji } \\
\text { z którymi obserwowano produkty } \\
\text { polimorficzne } \\
\text { Number of primers in the group in } \\
\text { which polymorphic products were } \\
\text { observed in the reaction }\end{array}$} & \multicolumn{2}{|c|}{$\begin{array}{l}\text { liczba produktów różnicujących od- } \\
\text { miany } \\
\text { Number of polimorfic PCR products }\end{array}$} \\
\hline & & & Elsanta & Senga Sengana \\
\hline $\mathrm{FvH}$ & 151 & 44 & 80 & 52 \\
\hline ChFvM & 135 & 97 & 178 & 155 \\
\hline $\mathrm{CO}$ & 48 & 27 & 35 & 42 \\
\hline $\mathrm{CX}$ & 33 & 15 & 20 & 16 \\
\hline FvA & 29 & 14 & 23 & 17 \\
\hline FvB & 27 & 18 & 45 & 30 \\
\hline $\mathrm{FvC}$ & 27 & 13 & 37 & 25 \\
\hline
\end{tabular}

W genomie odmiany 'Elsanta' dla wszystkich badanych grup markerów molekularnych, zidentyfikowano łącznie 418 alleli polimorficznych, natomiast w genomie odminay 'Senga Sengana' 337 alleli. Przeprowadzone badania potwierdzają wysoki stopień heterozygotyczności genomów obu wytypowanych do badań odmian.

\section{Aanliza populacji mapującej. Uzyskana mapa gentyczna badanych genomów.}

Do badań wykorzytsano matryce DNA wyizolowane $\mathrm{z}$ genomów form rodzicielskich, dla których potwierdzono wysoki poziom zróżnicowania genetycznego oraz $\mathrm{z}$ roślin potomnych, uzyskanych w wyniku ich krzyżowania. W reakcji z 44 wybranymi markerami SSR zidentyfikowano 53 allele, które segregowały w genotypach populacji mapującej. $\mathrm{Na}$ podstawie analizy rozkładu i frekwencji rekombinacji, oznaczono położenie i dystans mapowy loci tych alleli (Tab. 3). Skolekcjonowane dane użyto do przygotowania 'szkieletu' mapy genomów odmian 'Elsanta' oraz 'Senga Sengana'. 
Zintegrowana mapa genetyczna skonstruowana dla populacji 'Elsanta' $\times$ 'Senga Sengana' zawiera łącznie 27 grup sprzężeń (LG, Linkage groups), wykazujących wysoki stopień homologii do: chromosomów II i VI (LG2 i LG6 obejmowały homologi a-d), chromosomów I, III i VII (LG1, LG3 i LG7 obejmowały homologi a-c) oraz chromosomów IV i V (LG4 i LG5 obejmowały homologi a i b) opracowanych dla gatunku Fragaria.

Łącznie, na chromosomie I udało się zlokalizować loci 7 markerów, na chromosomie II - osiem, na chromosomie III i VI - po dziesięć, na chormosomach IV i V - po pięć, a na chromosomie VII - loci czterech markerów SSR. Wielkość uzyskanego zmapowanego fragmentu genomu (bin map) wyniosła 1 033,50 cM (Rys. 2).

Tabela 3

Table 3

Wyniki analizy rozkładu alleli i frekwencji rekombinacji w populacji mapującej oraz dystans genetyczny zidentyfikowanych loci markerów SSR.

Allele distribution, recombination frequency in the mapping population and genetic distance of identified SSR markers.

\begin{tabular}{|c|c|c|c|c|c|c|}
\hline $\begin{array}{l}\text { Grupa sprzęż. } \\
\text { Linkage group }\end{array}$ & Locus1 & Locus2 & $\begin{array}{c}\text { Frekwencja } \\
\text { rekombinacji/od- } \\
\text { ległość mapowa } \\
(\mathrm{cM}) \\
\text { Recombination } \\
\text { frequency }(\mathrm{cM})\end{array}$ & $\begin{array}{l}\text { Typ segregacji } \\
\text { alleli w populacji } \\
\begin{array}{c}\text { Segregation type } \\
\text { of alleles }\end{array}\end{array}$ & $\begin{array}{c}\text { Test X2 } \\
\text { Chi-square test }\end{array}$ & $\begin{array}{l}\text { Rozkład alleli w } \\
\text { populacji } \\
\text { Alleles distribu- } \\
\text { tion in mapping } \\
\text { population }\end{array}$ \\
\hline \multirow{3}{*}{ LG1A } & EMFn049 & $\mathrm{FvC103}$ & 19 & nnxnp & 0.8 & $3: 1$ \\
\hline & EMFn049 & COBRA & 25 & nnxnp & 2.2 & $3: 1$ \\
\hline & $\mathrm{FvC103}$ & COBRA & 6 & mlxll & 7.8 & $3: 1$ \\
\hline \multirow{2}{*}{ LG1B } & COBRA & CO817054 & 24,3 & nnxnp & 0.3 & $3: 1$ \\
\hline & CO817054 & FEFv14-29 & 20,7 & mlxll & 4.9 & $3: 1$ \\
\hline \multirow{3}{*}{ LG1C } & BFACT003 & FvH4171 & 21,7 & mlxll & 0.2 & $3: 1$ \\
\hline & FvH4171 & ARSFL002 & 28,3 & nnxnp & 0.6 & $3: 1$ \\
\hline & BFACT003 & ARSFL002 & 50 & nnxnp & 10.4 & $3: 1$ \\
\hline \multirow{3}{*}{ LG2A } & ARSFL012 & CFVCT015 & 30 & $a b x a b$ & 3.0 & $1: 2: 1$ \\
\hline & ARSFL012 & BFACT002 & 42 & $a b x a b$ & 3.5 & $1: 2: 1$ \\
\hline & CFVCT015 & BFACT002 & 12 & nnxnp & 0.4 & $3: 1$ \\
\hline LG2B & EMFn214 & CFACT111 & 34,3 & mlxll & 3.5 & $3: 1$ \\
\hline LG2C & BFACT002 & ARSFL015 & 18,4 & mlxll & 0.1 & $3: 1$ \\
\hline LG2D & FvH4173 & CFVC0316 & 24,3 & mlxll & 1.7 & $3: 1$ \\
\hline \multirow{9}{*}{ LG3A } & UDF0001 & FvH4161 & 18,4 & nnxnp & 4.3 & $3: 1$ \\
\hline & UDF0001 & FvH4155 & 26,6 & mlxll & 0.2 & $3: 1$ \\
\hline & UDF0001 & FvH4177 & 46,4 & mlxll & 0.4 & $3: 1$ \\
\hline & UDF0001 & FvH4165 & 70,7 & mlxll & 2.1 & $3: 1$ \\
\hline & FvH4161 & FvH4155 & 8,2 & nnxnp & 0.2 & $3: 1$ \\
\hline & FvH4161 & FvH4177 & 28 & nnxnp & 0.0 & $3: 1$ \\
\hline & FvH4161 & FvH4165 & 51,6 & mlxll & 0.8 & $3: 1$ \\
\hline & FvH4155 & FvH4177 & 19,8 & mlxll & 0.7 & $3: 1$ \\
\hline & FvH4155 & FvH4165 & 43,4 & nnxnp & 2.3 & $3: 1$ \\
\hline \multirow{3}{*}{ LG3B } & FvH4177 & FvH4165 & 23,6 & mlxll & 2.6 & $3: 1$ \\
\hline & FvH4169 & BFACT036 & 44,3 & mlxll & 0.4 & $3: 1$ \\
\hline & FvH4163 & FvH4153 & 36 & nnxnp & 3.3 & $3: 1$ \\
\hline \multirow[t]{2}{*}{ LG3C } & FvH4163 & BFACT045 & 68 & nnxnp & 1.8 & $3: 1$ \\
\hline & FvH4153 & BFACT045 & 32 & $a b x a b$ & 5.8 & $1: 2: 1$ \\
\hline \multirow{3}{*}{ LG4A } & EMFn132 & FvH4164 & 34,3 & $a b x a b$ & 0.3 & $1: 2: 1$ \\
\hline & EMFn132 & FvH456 & 42 & $a b x a b$ & 3.6 & $1: 2: 1$ \\
\hline & FvH4164 & FvH4156 & 8 & nnxnp & 0.4 & $3: 1$ \\
\hline LG4B & CO816733 & EMFv007 & 21,7 & nnxnp & 0.0 & $3: 1$ \\
\hline
\end{tabular}


Tabela 3

Table 3

Wyniki analizy rozkładu alleli i frekwencji rekombinacji w populacji mapującej oraz dystans genetyczny zidentyfikowanych loci markerów SSR.

Allele distribution, recombination frequency in the mapping population and genetic distance of identified SSR markers.

\begin{tabular}{|c|c|c|c|c|c|c|}
\hline $\begin{array}{l}\text { Grupa sprzęż. } \\
\text { Linkage group }\end{array}$ & Locus 1 & Locus2 & $\begin{array}{c}\text { Frekwencja } \\
\text { rekombinacji/od- } \\
\text { ległość mapowa } \\
(\mathrm{cM}) \\
\text { Recombination } \\
\text { frequency }(\mathrm{cM})\end{array}$ & $\begin{array}{c}\text { Typ segregacji } \\
\text { alleli w populacji } \\
\begin{array}{c}\text { Segregation type } \\
\text { of alleles }\end{array}\end{array}$ & $\begin{array}{c}\text { Test X2 } \\
\text { Chi-square test }\end{array}$ & $\begin{array}{l}\text { Rozkład alleli w } \\
\text { populacji } \\
\text { Alleles distribu- } \\
\text { tion in mapping } \\
\text { population }\end{array}$ \\
\hline \multirow{3}{*}{ LG5A } & FvH4164 & BFFv09-11-02 & 18,4 & nnxnp & 4.1 & $3: 1$ \\
\hline & FvH4164 & EMFv018 & 26,6 & mlxll & 0.2 & $3: 1$ \\
\hline & BFFv09-11-02 & EMFv018 & 8,2 & mlxll & 5.5 & $3: 1$ \\
\hline LG5B & UDF009 & BFACT017 & 24,3 & nnxnp & 1.7 & $3: 1$ \\
\hline \multirow{10}{*}{ LG6A } & FvH4164 & FvH4160 & 18,4 & mlxll & 12.6 & $3: 1$ \\
\hline & FvH4164 & FvH4159 & 21,6 & nnxnp & 2.0 & $3: 1$ \\
\hline & FvH4164 & FvH4154 & 26,4 & nnxnp & 4.9 & $3: 1$ \\
\hline & FvH4164 & ARSFL100 & 50,7 & mlxll & 0.5 & $3: 1$ \\
\hline & FvH4160 & FvH4159 & 3,2 & nnxnp & 0.3 & $3: 1$ \\
\hline & FvH4160 & FvH4154 & 8 & mlxll & 2.9 & $3: 1$ \\
\hline & FvH4160 & ARSFL100 & 32,3 & mlxll & 0.6 & $3: 1$ \\
\hline & FvH4159 & FvH4154 & 4,8 & nnxnp & 0.1 & $3: 1$ \\
\hline & FvH4159 & ARSFL100 & 29,1 & mlxll & 4.3 & $3: 1$ \\
\hline & FvH4154 & ARSFL100 & 24,3 & abxab & 0.6 & $3: 1$ \\
\hline LG6B & FvH4180 & FvH4163 & 25 & mlxll & 2.5 & $3: 1$ \\
\hline LG6C & ARSFL002 & ARSFL022 & 28,1 & $a b x a b$ & 1.1 & $1: 2: 1$ \\
\hline LG6D & EMFn017 & ARSFL022 & 34,9 & nnxnp & 0.0 & $3: 1$ \\
\hline LG7A & BFACT004 & EMFn213 & 25,2 & nnxnp & 2.4 & $3: 1$ \\
\hline \multirow{2}{*}{ LG7B } & ARSFL011 & EMFn213 & 7,1 & nnxnp & 5.2 & $3: 1$ \\
\hline & EMFv021 & EMFn213 & 15,5 & mlxll & 0.2 & $3: 1$ \\
\hline
\end{tabular}

Rys. 2. Schemat szkieletu zintegrowanej mapy 'Elsanta' × 'Senga Sengana'.

Fig. 2. The 'skeleton' (bin map) of the integrated genetic map of 'Elsanta' × 'Senga Sengana'.

\begin{tabular}{|c|c|c|c|}
\hline ELSS I & ESS LG1A & ESSLG1B & ESSLG1C \\
\hline 0,0 万ी EMFn0 49 & 0,0 万ी EMF n049 & 0,0 Tी COBRA & $0,0 \longrightarrow$ ВFАСТOOS \\
\hline $19,0-1$ FvC 103 & $19,0-\mathrm{FvC}_{103}$ & & \\
\hline \begin{tabular}{l|l}
21,7 & FvH 4171 \\
24,3 & Co 817054
\end{tabular} & & & - FvH4171 \\
\hline $27,4-1$ COBRA & $25,0 \perp$ COBRA & $-\infty 0817064$ & \\
\hline \begin{tabular}{l|l}
$45,0-$ BE Fv1 $4-29$
\end{tabular} & & 45.0 ○ BEFv 14.29 & \\
\hline & & & 50,0 — ARSFLOO2 \\
\hline
\end{tabular}


BIULETYN IHAR Nr 291 / 2020 Przygotowanie populacji mapującej uzyskanej ze skrzyżowania odmian 'Elsanta' i 'Senga Sengana'...

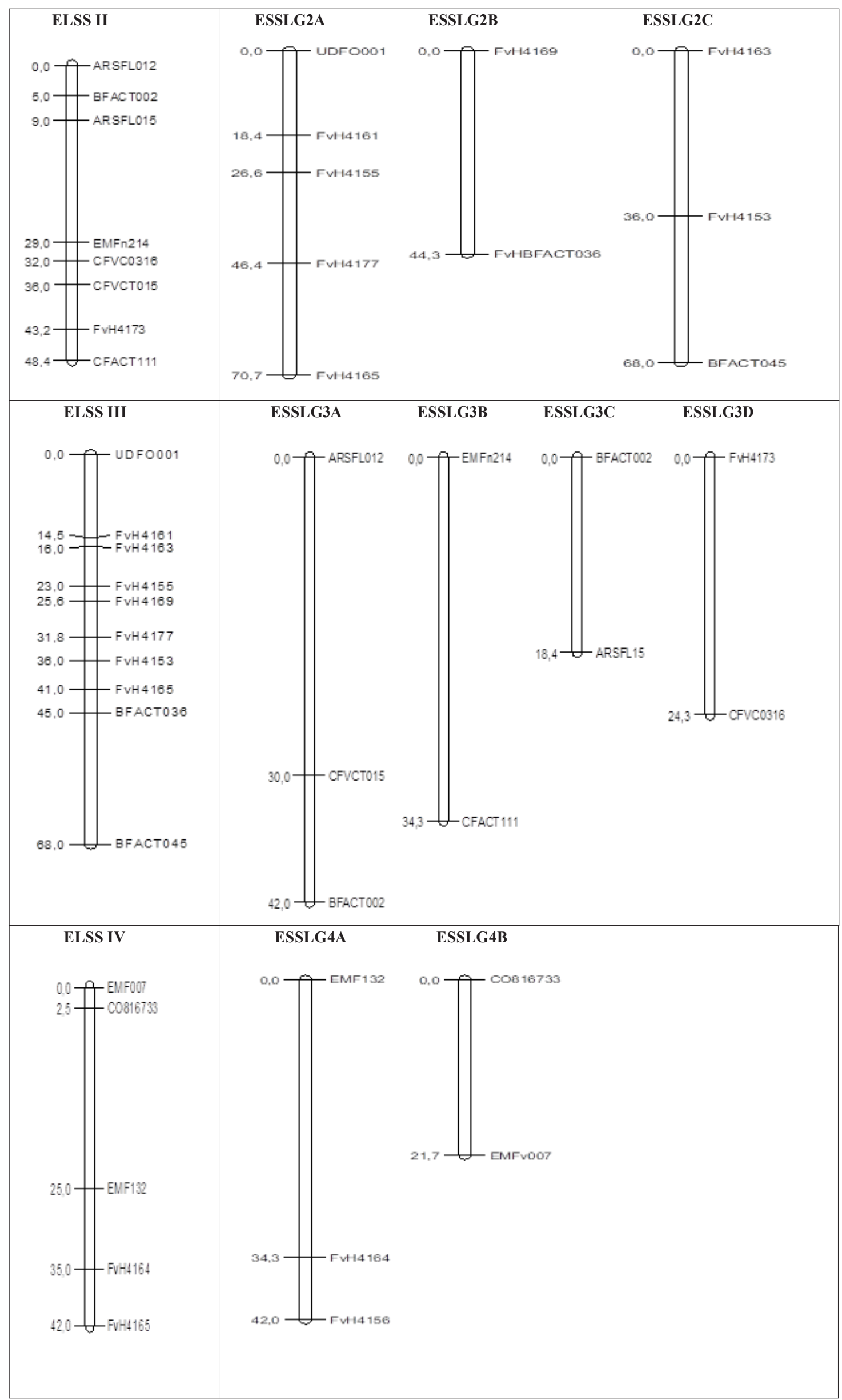




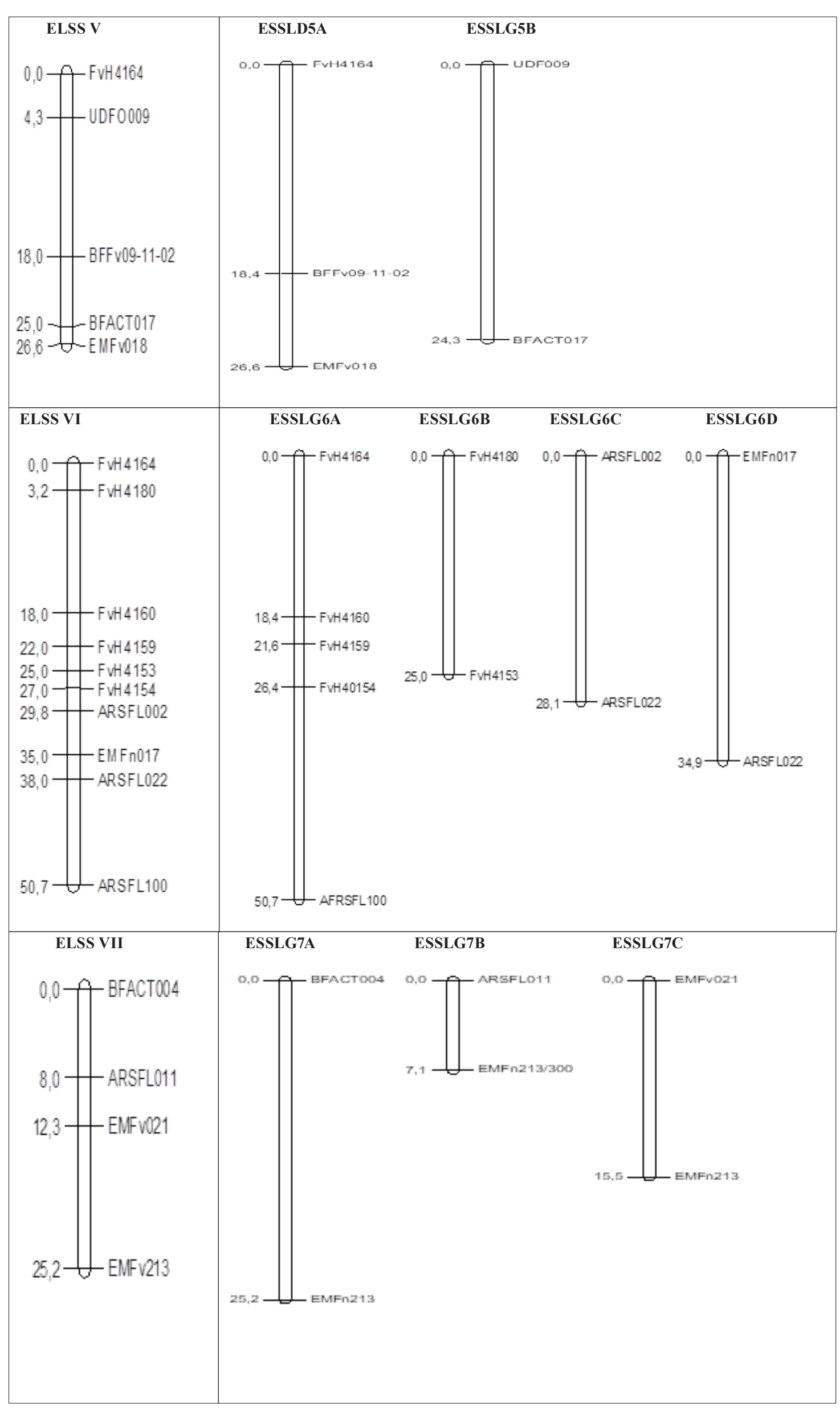




\section{Dyskusja}

Truskawka (Fragaria $\times$ ananassa Duch. ex Rozier) jest allopoliploidem (oktoploidem $2 \mathrm{n}=8 \mathrm{x}=56$ ) (Davis $\mathrm{i}$ in. 2007), którego poliploidyzacja podczas procesów ewolucyjnych doprowadziła prawdopodobnie do zaburzeń liczby chromosomów w gametach (Hancock 1999). Jej genom powstał na skutek przypadkowej hybrydyzacji dwóch gatunków poziomki Fragaria chiloensis Ehrh. (Chile) i Fragaria virginiana (USA).

W oparciu o badania cytogenetyczne i molekularne opracowano kilka modeli genomów allopoliploidalnych tego gatunku. Zgodnie $\mathrm{z}$ zapisem Y1Y1Y1Y1ZZZZ/Y1Y1Y1'Y1'ZZZZ (RousseauGueutin i in. 2009) i AAAABBCC (Fedorova 1946) w skład genomu $F$. × ananassa wchodzić mogą dwa (Y1, Z) bądź trzy rodzaje sub-genomów (Y1, Y1', Z lub A, B, C), a zapis AAA'A'BBB'B' (Bringhurst 1990) sugeruje udział nawet czterech $z$ nich $(A, A$, B, B') (Hummer i Janick 2009).

Skomplikowany układ genomu klasyfikuje truskawkę jako bardzo trudny obiekt dla zaawansowanych badań genetyczno-hodowlanych, czego skutkiem jest brak w literaturze doniesień na temat interakcji między genami warunkującymi różne cechy $F . \times$ ananassa. Niemniej jednak próby tworzenia zagęszczonych map genetycznych, służących „rozlokowaniu” genów warunkujących określone cechy na odpowiednich chromosomach, podejmowano w ostatnich latach w kilku współpracujących ośrodkach europejskich, USA i Japonii (Kole i Abbott, 2008, Sargent i in, 2011). Skutkiem tych badań jest dostępność map referencyjnych tego gatunku, sporządzonych dla roślin diploidalnych $F$. vesca i $F$. bucharica $\mathrm{FV} \times \mathrm{FB}$, (Sargent $i$ in. 2006, 2007, 2008; Zorrilla-Fontanesi i in. 2011) oraz oktoploidalnych $F \times$ ananassa (Isobe $\mathrm{i}$ in. 2013, Sargent i in. 2012; Davik i in. 2015). Mapy te zagęszczone są licznymi markerami mikrosatelitarnymi, które (uwzględniając zasadę kolinearności od 15 do 80\% (Mohamed 2014)) stanowią bazę danych do sporządzania map genetycznych genomów nowych odmian gatunku Fragraia.

Punktem krytycznym podczas generowania map genetycznych jest dobór populacji mapującej. Użycie populacji mapującej będącej wynikiem krzyżowania form rodzicielskich niewystarczająco zróżnicowanych pod względem fenotypowym i genotypowym, prowadzi do problemów $z$ interpretacją typu segregacji alleli, a w efekcie do błędnego odczytu położenia genów na mapie (Liebhard i Gessler, 2000; Rungis i in., 2005; Semagn i in., 2006; Kole i Abbott, 2008; Myles i in., 2009). Najprostszą metodą uzyskiwania populacji mapującej jest krzyżowanie heterozygotycznych form rodzicielskich CP (Cross Polination, zastosowana również w niniejszych badaniach), ale zależnie od typu dziedziczenia alleli cech stosowane są również populacje $\mathrm{F}_{2}, \mathrm{BC}$ czy $\mathrm{F}_{2: 3}$, wywodzące się z krzyżowania genotypów homozygotycznych (Knapp i in. 1990; Reiter i in., 1992; Yu i in., 2000; Philips i Vasil, 2001; Vinod, 2006; Hittalmani i in., 2008; Kole i Abbott, 2008). Przygotowanie populacji CP ma zwykle charakter kontrolowanego, wewnątrzgatunkowego krzyżowania genotypów o znanym pochodzeniu. Krytyczny podczas badania takiej populacji może być zbyt niski stopień polimorfizmu genetycznego form rodzicielskich oraz towarzyszące obcopylności występowanie potomstwa z nieplanowanych zapyleń (Van Ooijen i Voorrips, 2001). Dlatego przed podjęciem prac nad mapowaniem genomów 'Elsanta' i 'Senga Sengana' przeprowadzono (1) ocenę stopnia heterozygotyczności genomów form rodzicielskich oraz (2) analizę statusu mieszańców uzyskanych w wyniku ich krzyżowania.

W przeprowadzonych badaniach, dzięki analize porówanwszej wzorów prążkowych uzyskanych w teastach SSR-PCR na matrycach DNA rodziców oraz genotypów mieszancowych, pochodzenie z kontrolowanego zapylenia potwierdzono dla wszystkich badanych siewek. Poandto, wysoki stopień polimorfozmu pomiędzy krzyżowanymi genotypami obserwowany $w$ testach SSR-PCR, wskazuje na znaczny poziom heterozygotyczności odmian 'Elsanta' i 'Senga Sengana', co potwierdza ich przydatność do tworzenia populacji CP, stosowanej przy konstruowaniu map genetycznych.

Kolejnym ważnym elementem analizy populacji przydatnej do tworzenia map genetycznych genomów roślinnych jest także dobór markerów molekularnych (Ritter i in., 1990, Liebhard i Gessler 2000).

Zgodnie z definicją Schulmana i in. (2004), markery powinny być sprzężone $\mathrm{z}$ cechą, łatwe do wykrycia w testowanym materiale roślinnym i dziedziczone zgodnie z zasadami Mandla. Inna definicja zakłada również, że powinny one odzwierciedlać allele każdego z reprezentowanych przez nie genów/fragmentów genomu (Griffiths $i$ in. 1996). W niniejszych badniach wykorzystno zatem tylko markery molekularne, które wyraźnie różnicowały krzyżowane formy rodzicielskie, a zidentyfikowane dla nich allele haterozygotyczne segregowały w genotypach mieszańców.

Uzyskana mapa genetyczna zawiera łącznie 27 grup sprzężeń, na których zidentyfikowano loci 53 alleli polimorficznych, pokrywających $1033 \mathrm{cM}$ 
genomu truskawki. Należy zwrócić uwagę, że sporządzona dla oktoploidalnych genomów odmian 'Redguntlet' i 'Hapil' mapa referencyjna zawiera 30 grup sprzężeń (chromosomów homologicznych) (Sargent i in. 2012), a odmian 'Sonata' i 'Babette' -31 grup reprezentujących siedem chromosomów genomu Fragaria (Davik i in. 2015).

Uzyskana mapa stanowi istotną bazę dla podjęcia prac nad identyfikacją i potwierdzeniem obecności regionów regulujących cechy ilościowe (QTL, Quantitative Trait Loci) w genomach badanych odmian 'Elsanta' i 'Senga Sengana'.

Wiedza dotycząca lokalizacji precyzyjnych sekwencji w genomie pozwala na wskazanie potencjalnych markerów molekularnych, regulujących ważne agronomicznie cechy gatunku Fragaria, przydatnych do wczesnej selekcji genotypów hodowlanych wspierających konwencjonalne metody hodowli poprzez wdrożenie procesu MAS (Marker Assisted Selection) (Sargent i in. 2012).

Dotychczasowe, przeprowadzone m.in. dla odmian „Hanoye' badania potwierdzają bowiem obecność regionów QTL zawierających markery sprzężone z cechą jakości owoców truskawki, zidentyfikowane w obrębie chromosomów II, IV, V i VII (Zorrilla-Fontanesi i in. 2011, Verma $\mathrm{i}$ in. 2017) oraz z odpornością na różnego rodzaju patogeny, potwierdzone w regionach chromosomów III i VI (Denoyes Rothan i in. 2004, 2005; van Dijk i in. 2014; Davik i in. 2015).

\section{Wnioski}

1. Uzyskana populacja roślin potomnych pochodzących ze skrzyżowania odmian 'Elsanta' i 'Senga Sengana' stanowi wartościowy materiał do badań związanych z opracowaniem mapy genetycznej truskawki.

2. Wszystkie siewki z uzyskanej populacji mapującej reprezentowały wzory genetyczne wskazujące na segregację alleli pochodzących wyłącznie od form rodzicielskich 'Elsanta' i 'Senga Sengana'.

3. Sporządzony szkielet mapy genetycznej 'Elsanta' × 'Senga Sengana' może stanowić bazę do dalszej saturacji i do lokalizacji genów i identyfikacji regionów QTL sprzężonych z ważnymi cechami użytkowymi truskawki.

Badania finansowano ze środków projektu MRiRW: Badania podstawowe na rzecz postępu biologicznego w produkcji roślinnej, decyzja HOR. hn.802.4.2019 z dnia 14.05.2019 r.

Zadanie $n r 74$.

\section{Literatura}

Bringhurst, R. S. (1990). Cytogenetics and evolution in American Fragaria. Hortic. Sci. 25: 879-881.

Darrow, G. M. (1966). The Strawberry - History Breeding and Physiology. The New England Inst.for Med. Res.

Davik, J. Sargent, D. J., Brurberg, M. B., Lien, S., Kent, M., Alsheikh. (2015)a. A ddRAD based Linkage map of the cultivated strawberry, Fragaria annassa. PLOS ONE 10(9): doi:10.1371/journal.pone.0137746

Davis, T. M., DiMeglio, L. M., Yang, R. H., Styan, S. M. N., Lewers, K. S. (2007). Assessment of SSR transfer from the cultivated strawberry to diploid strawberry species: Functionality, linkage group assignment, and use in diversity analysis. J. Amer. Soc. Horti. Sci. 131: 506-512.

Denoyes-Rothan, B., Guerin, G., Lerceteau-Kohler, E., Risser, G. (2005). Inheritance of a race-specific resistance to Colletotrichum acutatum in Fragaria $\times$ ananassa. Phytopathology 95: 405-412.

Denoyes-Rothan, B., Lerceteau-Kohler, E., Guerin, G., Bosseur, S., Bariac, J., Martin, E., Roudeillac, P. (2004). QTL analysis for resistance to Colletotrichum acutatum and Phytophthora cactorum in octoploid strawberry $($ Fragaria $\times$ ananassa). Acta Hort. 663: 147-151.

Doyle, J. J., Doyle, J. L.. (1990). Isolation of plant DNA from fresh tissue. Focus, 12: 13-15.

FAOSta. (2019). Food and Agriculture http://www.fao.org/ faostat/en/\#data/QC

Federova, N. J. (1946). Cross ability and phylogenetic relationships in the main European species of Fragaria. Natl. Acad. Sci. USSR. 52: 545-7.5.

Griffiths, P. L., Dougan, G., Connerton, I. F. (1996). Transcription of the Campylobacter jejuni cell division gene ftsA. FEMS Micr. Lett. 143(1): 83-87.

Hancock, J. F.. (1999). Strawberries. CAB International, Oxford, U Hancock, K.

Hancock, J. F. (2008)., Temperate fruit crop breeding: germplasm to genomics, Springer Science +Business Media, B.V. New York. USA.

Hittalmani, S., Girish, T. N., Biradar, H., Maughan, P. J.. (2008). Mapping populations: Development, Descriptions and Deployment; Principles and Practices of Plant Genomics: Vol.1: Genome Mapping; Chapter 3, Kolle, C. and Abbott, A.G. Sci. Publishers USA: 69-92.

Hummer, K. E., Janick, J. (2009). Rosaceae: Taxonomy, economic importance, genomics. In: Folta, K. Gardiner, S. (eds), Genetics and Genomics of Rosaceae. Springer Science+Business Media, New York, USA, 1-18.

Isobe, S. N., Hirakawa, H., Sato, S., Maeda, F., Ishikawa, M., Mori, T., Yamamoto, Y., Shirasawa, K., Kimura, M., Fukami, M., Hashizume, F., Tsuji, T., Sasamoto, S., Kato, M., Nanri, K., Tsuruoka, H., Minami, C., Takahashi, C., Wada, T., Ono, A., Kawashima, K., Nakazaki, N., Kishida, Y., Kohara, M., Nakayama, S., Yamada, M., Fujishiro, T., Watanabe, A., Tabata, S. (2013). Construction of an 
integrated high density simple sequence repeat linkage map in cultivated strawberry (Fragaria $\times$ ananassa) and its applicability. DNA Res. 20: 79-92.

Kole, C., Abbott, A. G.. (2008). Fundamentals of plant genome mapping. W: Kole, C., Abbot, A. G., Principles and practices of plant genomics. Genome mapping. Science Publishers USA: 2-67.

Lerceteau-Kohler, E., Roudeillac, P., Markocic, M., Guerin, G., Praud, K., Denoyes-Rothan, B. (2002). The use of molecular markers for durable resistance breeding in the cultivated strawberry (Fragaria $\times$ ananassa). Acta Hort. 567: 615-618.

Liebhard, R., Gessler, C. (2000). Possible errors in genome mapping. Integrated Control of Pome Fruit Diseases IOBC wprs Biulletin 23(12): 127-135.

Masny A., Markowski J., Żurawicz E. (2002): Możliwości poprawienia jakości truskawek przez hodowlę nowych odmian. Zeszyty problemowe postępów nauk rolniczych 488:495-501

Mohamed, A. M. W. (2014). The genetic map of strawberry (Fragaria $\times$ ananassa) based on 'Elsanta' $\times$ 'Senga Sengana' mapping population. Praca doktorska. Instytut Ogrodnictwa, Skierniewice pp.108.

Myles, S., Peiffer, J., Brown, P. J., Ersoz, E. S., Zhang, Z., Costich, D. E., Buckler, E. S. (2009). Association mapping: Critical considerations shift from genotyping to experimental design. The Plant Cell 21. (2194)-2202.

Philips, R. L., Vasil, I. K. (2001). DNA based markers in Plants. Kluwer Acad. Publ, Dordrecht, The Netherlands 42: 227-238.

Reiter, R. S., Williams, J. G. K., Feldman, K. A., Rafalski, J. A., Tingey, S. V., Scolnik, P. A. (1992). Global and local genome mapping in Arabidopsis thaliana by using recombinant inbred lines and random amplified polymorphic DNAs. PNAS 89. (1477)-1481.

Ritter, E., Gebhardt, C., Salamini, F. (1990). Estimation of recombination frequencies and constructing of RFLP linkage maps in plants from crosses between heterozygous parents. Genetics 125: 645-654.

Rousseau-Gueutin, M., Gaston, A., Ännouche, A., Ainouche, A., Ainouche, M. L., Olbricht, K., Staudt, G., Richard, L., Denoyes-Rothan, B. (2009). Tracking the evolutionary history of polyploidy in Fragaria, L. (strawberry): new insights from phylogenetic analyses of low-copy nuclear genes. Mol. Phylogenet. Evol. 51: 515-530.

Rungis, D., Hamberger, B., Berube, Y., Wilkin, J., Bohlmann, J., Ritland, K. (2005). Efficient genetic mapping of single nucleotide polymorphisms based upon DNA mismatch digestion. Molecular Breeding 16: 261-270.

Sargent, D. J., Cipriani, G., Vilanova, S., Gil-Ariza, D., Arús, P., Simpson, D. W., Tobutt, K. R., Monfort, A. (2008). The development of a bin mapping population and the selective mapping of 103 markers in the diploid Fragaria reference map. Genome 51: 120-127.

Sargent, D. J., Clarke, J., Simpson, D. W., Tobutt, K. R., Arús, P, Monfort, A., Vilanova, S., Denoyes-Rothan, B., Rousseau, M., Folta, K. M., Bassil, N. V., Battey, N. H. (2006).
An enhanced microsatellite map of diploid Fragaria. Theor. Appl. Genet. 112. (1349)-1359.

Sargent, D. J., Kuchta, P., Lopez Girona, E., Zhang, H., Davis, T. M., Celton J. M., Marchese, A., Korbin, M., Folta, K., Shulaev, V., Simpson, D. W. (2011). Simple Sequence Repeat Marker Development and Mapping Targeted to reviously Unmapped Regions of the Strawberry Genome Sequence. Crop Science Society of America - The Plant Genome 4:165-177.

Sargent, D. J., Passey, T., Šurbanovski, N., Girona, L. L., Kuchta, P., Davik, J., Harrison, R., Passey, A., Whitehouse, A. B., Simpson, D. W. (2012). A microsatellite linkage map for the cultivated strawberry (Fragaria $\times$ ananassa) suggests extensive regions of homozygosity in the genome that may have resulted from breeding and selection. Theor. Appl. Genet. 124. (1229)-1240.

Sargent, D. J., Rys, A., Nier, S., Simpson, D. W., Tobutt, K. R. (2007). The development and mapping of functional markers in Fragaria and their transferability and potential for mapping in other genera. Theor. Appl. Genet. 114: 373-384.

Schulman, A. H., Flavell, A. J., Ellis, T. H. N. (2004). The Application of LTR Retrotransposons as Molecular Markers in Plants. In: Miller, W. J., Capy, P. (eds) Mobile Genetic Elements. Methods in Molecular Biology 260: Humana Press

Semagn, K., Bjornstad, A., Ndjiondjop, M. N. (2006). Principles, requirements and prospects of genetic mapping in plants. African Journal of Biotechnology 5(25). (2569)2587.

Verma, S., Zurn, J. D., Salinas, N., Mathey, M. M., Denoyes, B., Hancock, J. F., Finn, C. E., Bassil, N. V., Whitaker, V. M. (2017). Clarifying sub-genomic positions of QTLs for flowering habit and fruit quality in U.S. strawberry (Fragaria $\times$ ananassa) breeding populations using pedigree -based QTL analysis. Horticulture Research 4. (1706)2; doi:10.1038/hortres.2017.62

Van Dijk, T., Pagliarani, G., Pikunova, A., Noordij, Y., YilmazTemel, H., Meulenbroek, B., Visser, R., van de Weg, E. (2014). Genomic rearrangements and signatures of breeding in the allo-octoploid strawberry as revealed through an allele dose based SSR linkage map. BMC plant biology 14: 55.

Van Ooijen, J. W., Voorrips, R. E. (2001). JoinMap 3.0, Software for the calculation of genetic linkage maps. Plant Research International, Wageningen, The Netherlands, s. 78

Vinod, K. K. (2006). Genome mapping in plant populations. Proceedings of the training programme on "Modern Approaches in Plant Genetic Resources". - Collection,

Yu, K., Park, S. J., Poysa, V., Gepts P. (2000). Integration of simple sequence repeats (SSR) markers into a molekular linkage map of common bean (Phaseolus vulgaris L.). The Journal of Heredity 91(6): 429-434.

Zorrilla-Fontanesi, Y., Cabeza, A., Torres, A. M. (2011). Development and bin maping of strawberry genic-SSRs in diploid Fragaria and their transferability across the Rosoideae subfamily. Mol. Breed. 27: 137-156. 